\title{
Bicycle helmet use and preventing dental injury
}

\author{
Bicycle helmets - does the dental profession have a role in promoting their use? \\ H. R. Chapman and A. L. M. Curran Br Dent J 2004; 196: 555-559
}

\section{Objectives}

To review the available literature regarding the: epidemiology of bicycle related head injuries; consequences of head injuries; rates of cycle helmet use; impact of educational campaigns and legislation on usage rates; effectiveness of cycle helmets in protecting against head and facial injuries; arguments against the compulsory use of bicycle helmets.

\section{Data sources}

A computerised Medline search was conducted using the keywords: head injury, facial injury, bicycle helmets, accidents.

\section{Data selection}

All available information was considered.

Data synthesis

Data was collated manually.

\section{Conclusions}

The wearing of bicycle helmets contributes significantly to the prevention of head injuries (HI) and traumatic brain injury (TBI), particularly in children and adolescents. There is evidence to support the role of cycle helmets in the prevention of injuries to the middle third of the face and some dental injuries. There is a case for the implementation of legislation accompanied by educational campaigns to increase significantly the use of cycle helmets. The dental profession could: play an active role in promoting cycle helmet use; support calls for the compulsory wearing of cycling helmets, particularly for children; press for modification of helmet design and standards to increase protection of the face.

\section{IN BRIEF}

- The wearing of cycle helmets not only reduces the incidence and severity of head and brain injuries and their long-term consequences, but also facial and some dental trauma.

- Previous assessments of helmet efficacy have focussed on mortality rates; morbidity rates, including the effects of maxillofacial and dental trauma, have been neglected.

- The dental profession could contribute significantly to promotional campaigns.

- There is scope for further research into modification of helmet design to improve facial and dental protection.

\section{COMMENT}

Arguably, dentists have not engaged in injury prevention campaigns as much as might be expected, which makes this article very welcome. Few could argue against cycle helmet and other injury prevention initiatives by the dental team.

However, there are gaps in the evidence which must be addressed before the profession can argue that cycle helmets prevent dental and oral injury. In these days of evidence based public health it is not enough to state that '... it might be reasonable to surmise that a helmet that confers protection to the nose and maxilla is likely to confer some degree of protection to the upper dentition'. In fact, this seems unlikely since in the 1996 JAMA study cited no evidence of lower face (which included the upper lip) protection was found. Furthermore, a principal author has stated that the study included 121 cases with fractured teeth: $4.3 \%$ of those who were helmeted and $4.8 \%$ of those who were unhelmeted. The (non significant) odds ratio was 0.90 for helmet use $(95 \% \mathrm{Cl} 0.63-1.30)$ in this regard. ${ }^{1}$

In our study, also cited in the paper, of 104 cyclists treated for dental and face injury treated in South Wales ActE departments, injury was progressively more common from upper, through middle, to lower thirds of the face. Half of the patients sustained central facial injury (the nose, upper lip and upper anterior dentition). ${ }^{2}$

Our ex vivo studies include laboratory testing of all cycle helmet designs available in 1995 with regard to face protection. It was concluded that the dimensions of cycle helmets in relation to face coverage are crucial in influencing the extent to which facial protection is conferred, but that no current helmet designs were likely to prevent dental and oral injury. Downward projection of helmet design below the inferior limit for testing stipulated by British Standard 6863 was remarkably variable. ${ }^{3}$

Both epidemiologic and laboratory investigations suggest that the incorporation of a lower face bar, similar to Formula One helmet design, has the potential to prevent dental and lower third injuries. Such a helmet, the FaceSaver helmet has now been patented and is currently available. ${ }^{4}$ It remains to be seen however, whether such helmets are actually effective in terms of dental injury and whether there are unintended outcomes.

As for legislation, powerful injury prevention arguments are ranged against the arguments of civil libertarians. But arguments about legislation should not be allowed to undermine a main point of this paper which is relevant to all of us, that as health professionals, we should be committed to prevention beyond the confines of the mouth.

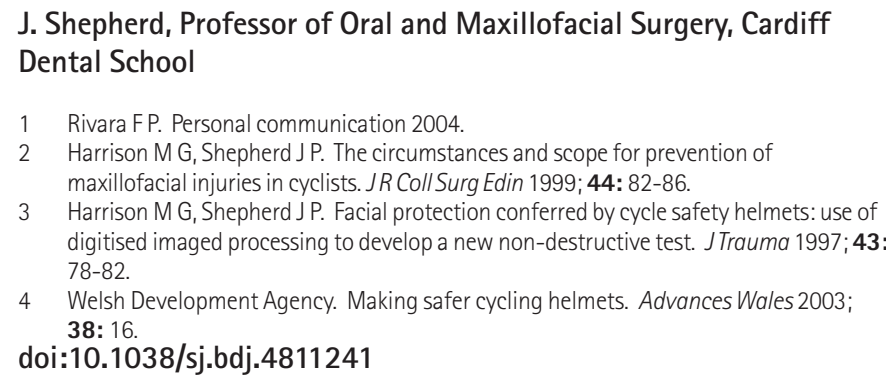

J. Shepherd, Professor of Oral and Maxillofacial Surgery, Cardiff Dental School

Rivara FP. Personal communication 2004

2 Harrison M G, Shepherd J P. The circumstances and scope for prevention of maxillofacial injuries in cyclists. J R Coll Surg Edin 1999; 44: 82-86.

3 Harrison M G, Shepherd J P. Facial protection conferred by cycle safety helmets: use of digitised imaged processing to develop a new non-destructive test. J Trauma 1997; 43 78-82.

4 Welsh Development Agency. Making safer cycling helmets. Advances Wales 2003; 38: 16 .

doi:10.1038/sj.bdj.4811241 